\title{
A simplified technique for short-term postcardiotomy pediatric extracorporeal membrane oxygenation
}

\author{
Christián Kreutzer, MD, Graciela Zapico, CCP, Christian Blunda, MD, \\ Maria I. Roman, MD, Willy M. Conejeros, MD, Adrian D. Revora, MD, \\ Jorge L. Simon, MD, Andres J. Schlichter, MD, and Guillermo 0. Kreutzer, MD, \\ Buenos Aires, Argentina
}

I $\mathrm{n}$ the current era, extracorporeal membrane oxygenation $(\mathrm{ECMO})$ is one of the appropriate tools for cardiopulmonary mechanical support after reparative surgery for congenital heart disease. ${ }^{1,2}$ Mechanical support is specially indicated for lesions and procedures in which transient postoperative myocardial dysfunction is expected and there is a reasonable chance of recovery. ${ }^{3}$ The usual postcardiotomy ECMO technique involves the replacement of the conventional extracorporeal circuit with a special closed ECMO circuit and oxygenator. We describe a modification of the cardiopulmonary bypass (CPB) circuit to create a closed ECMO circuit for short-term support, by using the standard parts of a conventional CPB circuit.

\section{Patients and Methods}

From November 2001 to June 2003, a specially designed CPB circuit was indicated in 13 patients in whom the possible need of postoperative ECMO was expected. The indications were anomalous left coronary artery arising from pulmonary artery, hypoplastic left heart syndrome, D transposition of the great arteries older than 4 weeks, and preoperative severe heart failure with inotropic use and assisted ventilation. Four patients (Table 1) who could not be weaned from CPB due to severe low cardiac output received short-term cardiac ECMO with this technique.

The modifications of the CPB circuit to allow its use as an ECMO circuit postoperatively were as follows:

1. A bypass containing an ECMO bladder (VRECMOS, Gish Biomedical, Rancho Santa Margarita, Calif) was inserted in the venous line, bypassing the cardiotomy reservoir (Figure $1, A$ ). The bladder was not primed to allow resterilization.

2. A longer S-70 polyvinylchloride tube was used for the raceway.

3. The hemofilter was placed in the arterial line (Figure 1, A).

From the Division of Cardiovascular Surgery, Ricardo Gutierrez Children's Hospital, Buenos Aires, Argentina.

Received for publication Aug 26, 2003; accepted for publication Sept 10, 2003.

Address for reprints: Christián Kreutzer, Instructor in Cardiovascular Surgery, Division of Cardiovascular Surgery, Ricardo Gutierrez Children's Hospital, MD Gallo 1330, 1425 Buenos Aires, Argentina (E-mail: ckreutz@intramed.net.ar).

J Thorac Cardiovasc Surg 2004;127:1200-2

$0022-5223 / \$ 30.00$

Copyright $\odot 2004$ by The American Association for Thoracic Surgery

doi:10.1016/j.jtcvs.2003.09.017

4. A pump console with interchangeable pump modules was used to allow removal and placement of the module on the ECMO cart (CINCO, Wakefield, Mass) (Figure 1, A).

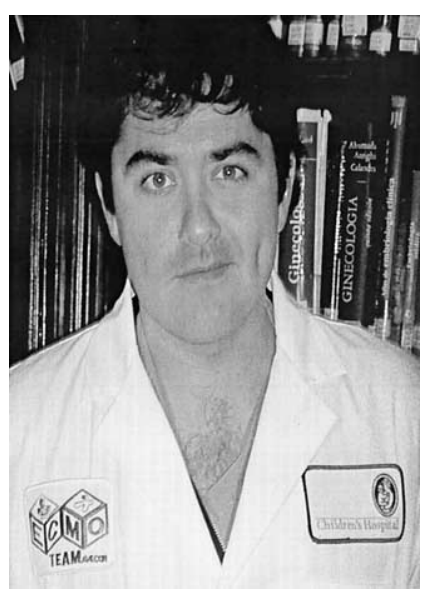

Dr Kreutzer
5. Medtronic Minimax

Plus oxygenators (Medtronic, Minneapolis, Minn) were utilized in patients 1,2 , and 3. Patient 4 received a Polystan Safe Micro oxygenator (Polystan AS Vaerløse, Denmark) (Figure 1, A).

$\mathrm{CPB}$ was conducted in the usual fashion with right atrial and aortic cannulation. When postbypass hemodynamics were not satisfactory, the patient continued on CPB via the closed-circuit ECMO. To achieve this, the line containing the bladder was blood-primed, the line to the cardiotomy reservoir was closed, and the line with the ECMO bladder was opened (Figure 1, B). The activated clotting time (ACT) was then dropped to 200 seconds by adding protamine sulfate to the ECMO prime. While the surgical team worked on hemostasis, the pump team placed the ECMO bladder in the ECMO bladder box and connected its electrical output to the pump module. The pump module was then removed from the pump console and placed with the bladder box in a battery-operated 2-level ECMO cart. The cardiotomy reservoir was removed and discarded and its in and out lines secured (Figure $1, B)$. Additionally, the oxygenator and the ECMO bladder box were mounted on the ECMO cart. When bleeding control was achieved, the sternum was left open and conventional dressings were applied in the wound. Patients were transported to the intensive care unit using the top level of the ECMO cart as a bed. ACT levels were kept at 180 seconds during the first postoperative day and subsequently raised to 200 seconds. Patient characteristics and outcomes can be seen in Table 1 .

\section{Discussion}

Use of ECMO had been restricted to centers in developed countries because its use involves specific equipment with a hardware cost of approximately US $\$ 2000$ per patient. That kind of expense prevented the use of ECMO in emerging economies, such as Argentina. The possibility of using the same circuit that was used in the extracorporeal circulation allows a significant drop in expenses, reaching an extra cost of only US\$200, which is the price of the ECMO bladder. If the ECMO circuit is not used, the bladder is not primed and can be resterilized. Thus, the only extra cost when ECMO is not needed is the ethylene oxide resterilization of the ECMO bladder. 

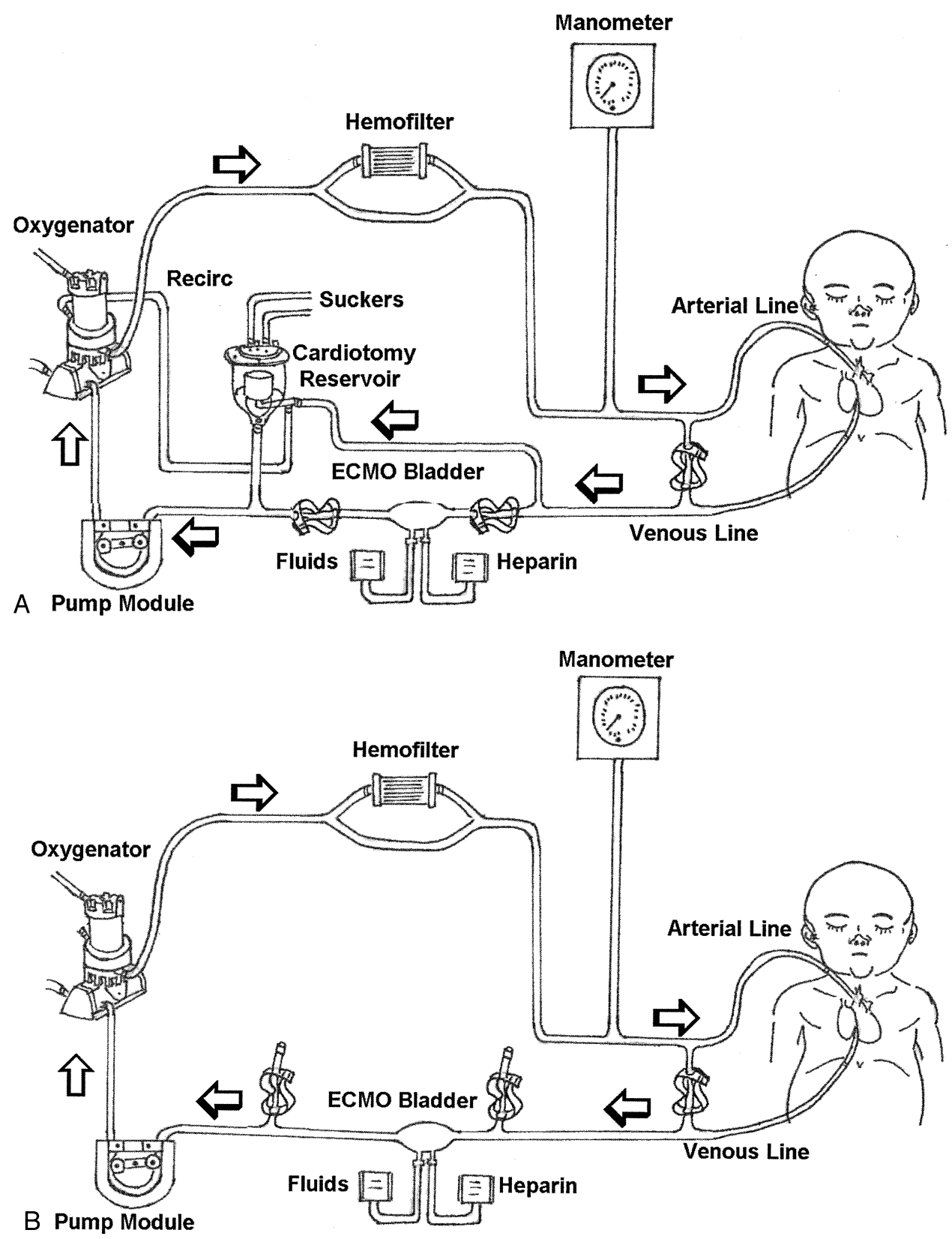

Figure 1. A, Modified circuit with cardiotomy reservoir bypass and hemofilter in arterial line during conventional CPB. B, Modified circuit during postcardiotomy ECMO.

In patients in whom the need of short-term ECMO is expected, this technique has several advantages other than cost itself, such as decreasing the use of blood products, hemodynamic stability since there is no need for reconnecting cannulas to the ECMO circuit, and ease of transportation to the cardiac intensive care unit. Another advantage of the method is the possibility of performing hemofiltration on conventional CPB and on ECMO using the same hemofilter.

Conventional oxygenators, like Medtronic Minimax Plus, ${ }^{4}$ have been used for short-term ECMO with acceptable durability. In our experience, these oxygenators last up to 6 days.
In conclusion, this method allows the use of postcardiotomy ECMO with minimal extra expense and may contribute to widespread use in underdeveloped countries.

Surgical care of patient 3 was undertaken by Dardo Fernandez Aramburu, MD.

\section{Addendum}

Since submission of this article, another patient successfully underwent postcardiotomy ECMO using this technique. The patient 
Table 1. Patient characteristics and outcome

\begin{tabular}{|c|c|c|c|c|c|c|c|}
\hline $\begin{array}{l}\text { Patient } \\
\text { no. }\end{array}$ & Age & $\begin{array}{c}\text { Weight } \\
\text { (kg) }\end{array}$ & Diagnosis & Procedure & $\begin{array}{l}\text { Duration of } \\
\text { ECMO (d) }\end{array}$ & Complications & Outcome \\
\hline 1 & $5 d$ & 3.1 & HLHS & Modified Norwood & 1 & none & Complete recovery \\
\hline 2 & $4 \mathrm{~d}$ & 3.5 & HLHS & Modified Norwood & 4 & VF, not recover Fx & Death \\
\hline 3 & $6 \mathrm{mo}$ & 5 & $\begin{array}{l}\text { Left Coron Ost } \\
\text { Atresia }\end{array}$ & LITA—LAD CAB & 6 & Bleeding, reexploration & $\begin{array}{l}\text { Weaned, death } \\
\text { 13th PO day }\end{array}$ \\
\hline 4 & $1 \mathrm{mo}$ & 2.4 & TGA-IVS & ASO & 4 & Bleeding, reoperation & Complete recovery \\
\hline
\end{tabular}

HLHS, Hypoplastic left heart syndrome; $F x$, function; Coron, coronary; Ost, ostium; LITA, left internal thoracic artery; $A D$, anterior descending coronary artery; $C A B$, coronary artery bypass; $P O$, postoperative; TGA, transposition of the great arteries; IVS, intact ventricular septum; $A S O$, arterial switch operation.

had the diagnosis of critical subaortic stenosis with poor ventricular function, received ECMO support for 12 hours, and had an uneventful recovery afterwards.

\section{References}

1. Duncan BW, Hraska V, Jonas RA, Wessel DL, Del Nido PJ, Laussen PC, et al. Mechanical circulatory support in children with cardiac disease. J Thorac Cardiovasc Surg. 1999;117:529-42.
2. Duncan BW. Mechanical circulatory support for infants and children with cardiac disease. Ann Thorac Surg. 2002;73:1670-7.

3. Black MD, Coles JG, Williams WG. Determinants of success in pediatric cardiac patients undergoing extracorporeal membrane oxygenation. Ann Thorac Surg. 1995;60:133-8.

4. Smedira NG, Moazami N, Golding CM, McCarthy PM, AppersonHansen C, Blackstone EH, et al. Clinical experience with 202 adults receiving extracorporeal membrane oxygenation for cardiac failure: survival at five years. J Thorac Cardiovasc Surg. 2001;122: 92-102. 